\title{
O CUIDADO NAS PRÁTICAS DOS PROFISSIONAIS EM CIRURGIA BARIÁTRICA
}

\author{
CARE IN PRACTICE OF PROFESSIONALS IN BARIATRIC SURGERY
}

\section{Laryssa Rodrigues de Oliveira ${ }^{\mathrm{a}^{*}}$, Sônia Ayako Tao Maruyama ${ }^{\mathrm{b}^{*}}$, Eliziani Gonçalves da Silva ${ }^{\mathrm{c}^{* *}}$, Aldenan Lima Ribeiro Corrêa da Costa $\mathrm{d}^{\mathrm{d}^{*}}$ \\ åoliveira.Ir@hotmail.com, bsoniamaruyama@gmail.com, celizianisilva@gmail.com, daldenanlima@gmail.com \\ *Universidade Federal de Mato Grosso - Cuiabá (MT), Brasil \\ **Secretaria Municipal de Saúde de Cuiabá - Cuiabá (MT), Brasil}

Data de recebimento do artigo: 04/08/2017

Data de aceite do artigo: 23/08/2017

\section{RESUMO}

Este artigo descreve o cuidado nas práticas dos profissionais de saúde em cirurgia bariátrica. Fez-se um estudo de abordagem qualitativa, realizada a partir de um banco de dados de entrevistas com profissionais de saúde. A partir da análise temática evidenciaram-se duas categorias: o valor do corpo obeso e da alimentação; e a busca da relação compartilhada entre profissional, usuário e instituição. Na primeira, os valores de corpo obeso e alimentação não saudável foram ressaltados; na segunda, os profissionais reconheceram que é preciso corresponsabilizar o usuário, utilizar de diferentes modos de atuar para significar a cirurgia e as suas repercussóes e que o modo integrado em equipe colabora para a ação cuidativa. Concluímos que, embora a cultura biomédica prevaleça e, desse modo, os cuidados biomédicos sejam os mais considerados, observou-se também a consideração de alguns aspectos socioculturais na realização do cuidado das pessoas no contexto da cirurgia bariátrica, assim incorporando o cuidado em suas práticas.

Palavras-chave: Prática profissional; obesidade; cirurgia bariátrica.

\section{ABSTRACT}

This article describes the care in health professionals' practices in bariatric surgery. This qualitative study was carried out from a database of interviews with health professionals. The thematic analysis demonstrated two categories: the valuation of the obese body and feeding; and the pursuit of a relationship shared between professional, user and institution. In the first one, the values of obese body and unhealthy diet were highlighted; in the second, professionals recognized that is necessary to hold the user co-responsible, to use different ways of acting to signify the surgery and its impacts, and that the integrated team mode collaborates to the caring action. We conclude that although the biomedical culture prevails, and thus biomedical care is the most considered, there was also some consideration of socio-cultural aspects in the performance of care to people in the context of bariatric surgery, therefore allying care in their practices.

Keywords: Professional practice; obesity; bariatric surgery. 


\section{Introdução}

No mundo, a obesidade tem sido relacionada a 3,4 milhóes de mortes de adultos por ano ${ }^{1}$. O seu tratamento inclui orientação psicológica e dietética, atividade física e uso de fármacos antiobesidade, porém os obesos mórbidos nem sempre logram êxito quando requerem o tratamento cirúrgico - a cirurgia bariátrica ${ }^{2}$. Essas cirurgias feitas pelo Sistema Único de Saúde (SUS) vêm crescendo: passaram de 4.489, em 2010, para 6.493, em 2013, um aumento de $45 \%{ }^{3}$. Com esse crescimento, aumentou também o número de profissionais envolvidos nesse tratamento ${ }^{4}$.

A prática dos profissionais de saúde tem por referência a cultura biomédica, mas também o contexto sociocultural, o valor do corpo, uma marca social. No modelo biomédico fragmenta-se o doente em sintomas objetivos, não alcançando a subjetividade, a complexidade e a singularidade da vivência humana experiencial e existencial 5 . No entanto, consideramos que, em alguma medida, os profissionais se envolvem com a experiência dos pacientes, sendo este o intento deste estudo.

O profissional, ao transcender os limites da cultura biomédica, consegue alcançar uma relação humanizada, de cuidado ${ }^{6}$, e ao incluir os aspectos existenciais, alcança a dimensão sociocultural, aliando, assim, à sua prática o cuidado ${ }^{4}$. Em busca da humanização na saúde, procuramos compreender nos profissionais dessa área a sua dimensão social e cultural, suas crenças, seus comportamentos e as suas formas de entender a pessoa que cuida. O cuidado é objeto do trabalho da enfermagem e difere das práticas dos outros profissionais.

O cuidado em saúde envolve

uma atitude prática frente ao sentido que as açóes de saúde adquirem nas diversas situaçôes em que se reclama uma ação terapêutica, isto é, uma interação entre dois ou mais sujeitos visando o alívio de um sofrimento ou o alcance de um bem-estar, sempre mediada por saberes especificamente voltados para essa finalidade. ${ }^{7}$

Com base nessas considerações, questionamos: como o cuidado se insere nas práticas dos profissionais de saúde? Como o cuidado é evidenciado nas narrativas destes?

O SUS, hierarquizado e organizado, ainda não atende às necessidades da população, apesar de haver experiências exitosas. $\mathrm{O}$ trabalho na saúde deveria articular suas práticas e o cuidado, porém percebemos um distanciamento entre eles, principalmente se questionarmos os usuários sobre o sentimento de serem cuidados pelos profissionais. É indiscutível que as mudanças no sistema de saúde dependem de transformaçóes em espaços mais amplos da sociedade, no entanto elas podem ser realizadas na prática e nos próprios locais de trabalho ${ }^{8}$. Assim, objetivamos descrever o cuidado com a saúde nas práticas de profissionais em cirurgia bariátrica. Evidenciar a prática profissional e o cuidado, a importância das narrativas dos profissionais, seus movimentos e suas relaçóes são as contribuiçóes deste estudo.

\section{Metodologia}

Fez-se um estudo de abordagem qualitativa que utilizou o banco de dados da pesquisa Práticas profissionais em cirurgia para redução de peso $0^{4}$, a qual teve como contexto um ambulatório de cirurgia bariátrica de um hospital público de Mato Grosso. As entrevistas, coletadas entre abril e julho de 2013, de sete profissionais (psicóloga, nutricionista, médico, enfermeira) totalizaram 115 páginas. A idade dos profissionais variou de 28 a 50 anos, o tempo de profissão entre 8 meses e 26 anos e o tempo de trabalho com pessoas obesas de 5 meses a 11 anos.

Foi realizada a análise temática", que "consiste em descobrir os núcleos de sentido que compóem uma comunicação"; portanto palavras, frases e expressões relacionadas ao objeto de estudo foram separadas. Realizamos leituras flutuantes e a análise propriamente dita. A leitura teve por objetivo identificar e extrair das narrativas os trechos que indicariam elementos do cuidado, manifestaçôes do sofrimento e da fragilidade, como: sofrimento grande, o físico provoca, obeso sofre, autoestima. Em seguida, buscamos dar sentido aos temas: corpo obeso, alimentação não saudável, implicação social, uso de verbos para orientar e dinâmica do trabalho. Isso nos conduziu aos eixos "O valor do corpo obeso e da alimentação" e "Relação compartilhada entre profissional, usuário e instituição".

A pesquisa atendeu à Resolução no 466 de 12 de dezembro de 2012, do Conselho Nacional de Saúde ${ }^{10}$, sendo aprovada sob protocolo $\mathrm{n}^{\circ}$ 194.292/CEPHUJM/2013. Visando manter o sigilo, os participantes foram identificados com a letra $\mathrm{P}$ seguida de número arábico sequencial.

\section{Resultados e discussão}

As narrativas dos profissionais revelam como eles veem a pessoa que busca pela cirurgia bariátrica e como descrevem a instituição de saúde que "cuida" dela. 


\section{O valor do corpo obeso e da alimentação}

Os profissionais valorizaram os temas: corpo obeso, alimentação não saudável, implicação social e responsabilização da pessoa. O corpo obeso é socialmente negativo, por isso o relacionam ao sofrimento:

\section{sofrem bastante, $[\ldots]$ chegam angustiados. (P3)} a gente vê a dificuldade que estas pessoas têm [...] na locomoção. (P7)

A relação entre corpo obeso e sofrimento é evidenciada quando os profissionais associam os limites que a obesidade causa à mobilidade, marcando socialmente essas pessoas por eles observadas. Nesse sentido, o corpo é significativo pois "comporta diferentes concepções, que penetram os diversos saberes e práticas de cura expressos nas várias racionalidades médicas (ocidentais e orientais), interferindo nas concepções de saúde e doença" ${ }^{11}$. A forma do corpo obeso afeta subjetivamente $\mathrm{o}$ indivíduo:

é um sofrimento muito grande e o fisico provoca tudo isso $[\ldots]$ o paciente obeso realmente ele sofre muito. (P6)

A pessoa vem com baixa autoestima, vem insegura. (P2)

Os profissionais reconhecem que há nos pacientes alteração na autoestima e insegurança - revelando que há um modo sensível de olhar e escutar -, o que implica a necessidade de suporte emocional na terapêutica ${ }^{12}$. Para os entrevistados, o corpo obeso apresenta alterações físicas que requerem ajuda profissional:

ela tem dificuldade de locomoção fisica, ela tem certas diffculdades de flexibilidade, falta de ar, doenças do tipo pressão alta, diabetes. (P2)

Esse reconhecimento colabora para o entendimento dos profissionais sobre a importância da cirurgia:

já vem pra cirurgia mesmo [...] vem pra melhorar [...] é a última instância. (P4)

chega aqui já como uma última alternativa. (P2)

Tal valorização os mobiliza, afetando a forma como acolhem e buscam dar resolutividade ao sofrimento dos pacientes. Porém entendem a cirurgia como invasiva e mutilante:

infelizmente é a melhor técnica. (P5)

tirar um pedaço do seu estômago. (P4)

Eu falo infelizmente porque eu acho agressiva ainda. (P5)
A agressividade é relacionada à intervenção num corpo tido como "saudável", "sem doença", "corpo hígido", e não à compreensão de que a pessoa obesa sofre pelas repercussóes sociais e morais dessa prática. A relação entre o corpo e os valores de saúde, a doença, o doente e o objeto de intervençáo - reveladores dos significados presentes na forma como os profissionais conduzem suas práticas - está fortemente fundamentada no modelo biomédico. Essa perspectiva tem orientado o profissional para a necessidade de acompanhamento contínuo e organizado do doente por especialistas, para monitorar as complicaçóes no pós-operatório ${ }^{13}$.

Um acompanhamento de vitaminas, de reposiçôes. (P1) nem sempre a pessoa está preparada para emagrecer, outras vezes ela emagrece, mas ela continua se sentindo obesa né?! (P2) se manter magro é muito difícil. (P4)

Essa valorização dos especialistas revela o compromisso no acompanhamento dos pacientes:

Vamos tentar fazer com que os resultados sejam os melhores possiveis. (P5)

O cuidado está sob responsabilidade do profissional na medida em que este valoriza a necessidade de acompanhamento, reforçando o seu vínculo com essas medidas adicionais. No cuidado, o vínculo e a responsabilidade são fundamentais ${ }^{12}$. Os profissionais, ao reconhecerem as consequências físicas e sociais do pós-cirurgia, como a flacidez da pele, as alteraçôes psicoemocionais e intestinais, valorizam o paciente como ser social, cuidando-o.

tô ficando mole, só pele. (P4)

vão emagrecendo e se vendo flácidos [...] ficam chateados. (P5)

porque você tira parte do intestino onde ocorre a absorção. (P4)

apresentaram assim queda de cabelo né. (P4)

Mudança de corpo né?! Que é sempre uma distorção da imagem corporal. (P2)

Os profissionais buscam que a cirurgia alcance um corpo sem marcas sociais, o que influencia positiva e emocionalmente as interaçóes sociais médicos-pacientes, como revelam os seguintes trechos:

elas estâo super felizes, todas vêm maquiadinha, autoestima melhora, vem com umas roupinhas mais modernas. (P3) melhora da qualidade de vida [...], com os ganhos [...] conseguir voltar a trabalhar. (P1)

o paciente no pós-cirúrgico ele tendo sucesso, ele estando satisfeito. (P4) 
As pessoas que se submetem à cirurgia melhoram no vestir-se, no mobilizar-se, na autoestima, no trabalho, na vida, como descrevem:

não é só rever a relação com a comida, com a bebida, é rever a sua relação com a vida. (P6)

O cuidado consiste em possibilitar essa positividade, expressa na voz daqueles que passaram pela cirurgia. $\mathrm{Na}$ medida em que o profissional se empenha e se motiva, evidencia-se a circularidade do cuidado: o profissional cuida do doente e, ao ver a satisfaçáo da pessoa cuidada, também se sente cuidado por ela.

O cuidado se insere nas práticas profissionais quando há o reconhecimento sobre o corpo socialmente desvalorizado do paciente, cuja intervenção, embora negativa, oportuniza melhoria na sua vida e nas suas interaçôes. O "cuidar da saúde de alguém é mais que construir um objeto e intervir sobre ele. Para cuidar há que se considerar e construir projetos" 14

Outro aspecto valorizado pelos profissionais diz respeito à alimentação não saudável:

desde de criança você tem hábitos de vida de alimentação errados [...] não tem horário. (P4)

tem questâo cultural! [...] desde pequena aprendem isso [...] a comer muito e rápido! (P6)

Evidencia-se a relação entre a forma de alimentação e a infância, os hábitos, os horários, a educação e o aprendizado, revelando que esse aspecto é assimilado nos espaços que as pessoas compartilham, sendo, portanto, construído. O cuidado está em valorizar a alimentaçâo como um comportamento moldado no contexto social e cultural de cada um, ou seja, um hábito, que necessita ser ressignificado. Nesse processo, destacam-se a importância da informação, da orientação, da prática e do tempo. Os profissionais salientam que há facilidade de acesso à alimentos calóricos:

uma sociedade que impóe, é engraçado isso, que contradição, um paradoxo da... Sabe? Complicado, por quê? Oferece um mundo de comida. (P6)

A sociedade é consumista, pragmática e capitalista e valoriza a alimentação; por isso os entrevistados destacam que, se o alimentar é valor aprendido, é importante o seu acompanhamento pelo profissional. Há o reconhecimento da potencialidade do ser humano nesse aspecto. Os profissionais valorizam os comportamentos que têm êxito no cuidado: porque se ele náo conseguir se preparar no pré-cirúrgico com certeza ele vai ter dificuldade no pós-cirúrgico. (P2)

Tudo se comemora comendo e bebendo, então é difícil a pessoa manter depois do emagrecimento o seu peso. (P4)

O cuidado está em reconhecer que o comportamento das pessoas está relacionado ao aprendizado sobre os valores e as crenças de cada um, construído nos espaços sociais ao longo de suas trajetórias biográficas. O comportamento relaciona aspectos sociais e culturais, e estando, portanto, enraizado, desafia o profissional na ressignificação desse hábito, como narra este entrevistado:

Na verdade é mais fácil comer, né, do que pensar, rever, se elaborar, mudar hábitos. (P6)

A cirurgia é feita no físico, é reduzir o estômago, mas a questão é comportamental. Então se você não faz toda uma revisão de valores e a sua relação com a comida, com a bebida, não vai aguentar. (P6)

A forma de nos alimentarmos é socialmente construída, por isso, enraizada. O comer se constitui como uma açáo concreta, de incorporação dos alimentos e de seus significados ${ }^{15}$. A complexidade do humano está presente nesse reconhecimento sociocultural do alimentar-se, assim como na percepção de que a autonomia da pessoa também influencia nesse comportamento.

Ele tem livre arbitrio. Ele pode comer depois da cirurgia, um garfo comum cheio. Só que ele vai ter a consequência disso! Ele vai passar muito mal! (P6)

Juntamente com o valor do corpo e da alimentação, os profissionais também cuidam ao reconhecer que a pessoa obesa tem nas relações uma implicaçáo social a discriminaçáo. Por isso ela busca pelo ideal de corpo valorizado pela sociedade ${ }^{16}$. Nesta narrativa, um entrevistado descreve:

existe um sofrimento [...] emocional também. Sabe social, emocional, então existe muito preconceito. (P6)

O cuidado profissional se baseia em reconhecer essa dimensão social e cultural do corpo da pessoa obesa e o procedimento cirúrgico como meio de retorno à vida social:

você vê a pessoa que consegue voltar a sair, você vê pessoa que consegue voltar a ter relacionamentos pessoais e amorosos [...] volta a trabalhar. (P1)

passa a ter uma vida diferente, com muito mais qualidade de vida. (P2) 
O profissional cuida do paciente ao possibilitar a reflexáo dessa pessoa sobre seu comportamento na vida social e a revisão dos seus valores:

que ele tenha maior percepção dele mesmo. (P6) o problema da obesidade não é o estômago. O problema éo que está na cabeça. Muitas vezes. Na compulsäo, na ansiedade, na depressão. (P5)

No processo de significação/ressignificação enfatiza-se a responsabilização do indivíduo, o que configura um cuidado por implicar um movimento ativo da pessoa:

Então você é coparticipativo do seu tratamento também. Não é só tomar remédio, não é só deixar que o médico trate disso. (P5)

A cirurgia é um instrumento, é uma ferramenta, mas entra a parte da pessoa... Exatamente. [...] o paciente precisa se comprometer. (P6)

Embora o serviço pós-operatório seja organizado com espaço, ambiente, recursos materiais e humanos e acompanhamento especializado, os profissionais consideram a participaçáo ativa da pessoa e a corresponsabilizaçáo como fundamentais. Compartilhar o cuidado com a saúde entre profissional e usuário extrapola a dimensão assistencial: requer envolvimento, acolhimento, reconhecimento e trocas de experiências entre as pessoas envolvidas, pois são experiências existenciais mediadas por questóes sociais e culturais de cada uma delas.

\section{Buscando uma relação compartilhada entre profissional, usuário e instituição}

A relaçáo profissional-usuário foi marcante, pois evidenciou a forma como estes atuam, a finalidade e o tempo limitado da sua prática:

preparar para a cirurgia. (P2)

eu tento [...] não é tão fácil porque é só uma ou duas consultas. (P1)

Evidenciou também as repercussões decorrentes da cirurgia para a pessoa obesa:

o primeiro mês que é mais complicado. (P2)

ela pode ter dificuldade de absorver vitaminas [...], então eu sempre tento trabalhar essa questão né?! (P2)

Os profissionais descrevem a sua atuação em um contexto particular, os limites da sua prática e o esforço para efetivá-las, em especial no período pós-operatório, que é crítico para o paciente:

eu peço para eles voltarem nos primeiros quinze dias, porque é a etapa mais crítica. É justamente onde eles vão se ver com a restrição alimentar, com as dores, com as consequências do pós-cirúrgico [...] acompanho uns vinte, trinta dias pra ver a reintrodução dos alimentos. (P2)

As entrevistas sinalizaram os comportamentos dessas pessoas quanto às mudanças alimentares, à dor e às consequências após a cirurgia, sendo orientadas pelo conhecimento biomédico e pelo conhecimento decorrente de sua prática cotidiana. Esse reconhecimento relaciona a prática nesse contexto específico à sensibilidade e ao conhecimento científico. eles:

Os profissionais buscam "ver" a pessoa cuidada por

a gente explica bem o porquê desses requisitos, qual a função de cada coisa para que elas possam entender [...] se adequar o melhor possivel. (P2)

Tento conscientizar, levar esse paciente a refletir que isso nâo é uma pequena mudança. (P6)

Seu esforço se traduz pelo uso dos termos: explica bem, tento conscientizar, e o retorno desse cuidado é percebido quando o entrevistado infere que os pacientes possam entender e que ele possa levar esse paciente a refletir. Sua dedicação se relaciona ao tempo, ao momento, à busca por sensibilizá-los para a ressignificação, já que a cirurgia é agressiva e provoca mudanças desde os primeiros dias. Ressignificar é informar e educar em busca da reconstrução dos sentidos da vida ${ }^{17}$, e esse processo destaca a subjetividade como valor. Assim, destacamos a observação ${ }^{18}$ como modo de apreender esta dimensão durante o cuidado.

O cuidado se notabiliza quando o profissional demonstra apreender o comprometimento da pessoa que quer se submeter à cirurgia bariátrica:

Por mim não éliberado. Quando eu percebo que está fazendo só por que: "ah eu só estou um pouquinho gordinho", "eu estou com preguiça de fazer regime". Meu Deus! Está com preguiça de fazer regime! Então não vai conseguir depois fazer toda uma readaptaçáo de hábito, de comportamento. (P6)

Em especial, o profissional observa o comprometimento do paciente quanto ao tratamento, à alimentação e à cirurgia:

eu realmente insisto, eu tento fazer com que a pessoa pense mais, o que que ela tem feito, como ela se relaciona, que 
outros tipos de compensação, compensaçôes ela faz hoje em dia, não é só na comida e na bebida. (P6)

porque a gente orienta muito o paciente antes de fazer a cirurgia, eles vão para cirurgia consciente de que é a cirurgia né?! Que é uma mudança radical pra vida deles. (P4)

Estimular a responsabilização constitui o cuidado, quando se observam os movimentos comportamentais e reflexivos:

para gente entender melhor ele, fisicamente e emocionalmente, como que ele vai estar reagindo a esse processo. Eu pontuo [...] que ele vai ter alguns compromissos depois da cirurgia. (P6)

Esse acompanhamento na verdade não é só para preparar como que a pessoa vai vivenciar depois [...]. Mas é responsabilizá-lo pelo que pode acontecer e comprometer ela. (P2) Ai você vai bater duro até realmente ela fazer. (P2)

O cuidado é a prática de responsabilizar sobre o cuidado consigo, mediada pela comunicação verbal:

orientar eles da necessidade de que "oh daqui para frente tem que mudar hábitos [...] se não a coisa não vai ter resultado". (P1)

a gente perceber até onde dá para gente ir, que linguagem que dá para usar com o paciente, né. Dá para usar uma linguagem mais simples, ou mais elaborada. (P6)

a gente está $[\ldots]$ sempre orientando, sempre lembrando o que é alimentação saudável a cada vez que o paciente retorna, a gente no consultório a gente revê tudo as orientaçōes. (P4)

A comunicação verbal consiste em falar e escutar, um movimento dinâmico e sensível em que as pessoas envolvidas são subjetivamente implicadas. $\mathrm{Na}$ prática assistencial é possível descentrar a interação profissional a partir do usuário enquanto "objeto de intervenção" para focar nas "trocas mais amplas que ali se realizam" Neste trecho, destaca-se o uso de verbos:

A cirurgia é uma grande mudança, física, acarreta uma série de coisas na vida desse paciente, náo só físico como emocional. Então eu tento realmente mostrar pra ele isso. (P6)

Eu sempre explico assim também, que todo esse processo não é fácil, mas é possivel! [...] tento demonstrar a todo momento [...] na minha fala, pode não ser fácil, mas é possivel. (P6) eu tento mostrar que houve um desvio, diminuiu o estômago, isso aqui é irreversivel. [...] eu apresento novamente, seja num desenho, ou numa ilustração mesmo da cirurgia ou num vídeo, o que aconteceu por dentro, né, porque eles não têm esta consciência, ou às vezes esquecem mesmo né. (P5)

Nas narrativas, os entrevistados usam: demonstrar, explicar, apresentar, verbos que implicam dar visibilidade prática, tornar concreto o que se fala, incorporando ao discurso algo de real e palpável para a pessoa cuidada. Visam, assim, ampliar a sua atuação para além do alcance do resultado de um corpo magro, possibilitando a ressignificação de sentidos. São verbos que indicam o modo como se dá a prática e a açáo do cuidado e que evidenciam o diálogo - recurso terapêutico do cuidado profissional. Incorporar desenhos e vídeos subsidia a ressignificação sobre as mudanças no corpo e sobre as formas de se alimentar. Esses recursos também buscam dar concretude ao que se fala, visando tornar prática e realista a forma correta de alimentar-se:

aqui comigo [...] eu brinco que são tarefas. [...] a gente vai passando, na verdade, tarefas que vocês vão ter que ir fazendo [...] eu criei esse instrumento [...] é uma folhinha simples, mas pra ele sair daqui com um documento pra eles lembrarem, são vínculos, sair com algo daqui [...] eu trago também [...] um garfo normal, um garfo pequeno de sobremesa pra eles entenderem o que é reduzir quantidade, concretizar isso. (P6)

Os profissionais demonstram um processo de ensinar e aprender mediado pela ação do médico, que visa esclarecer "como" e "pra quê". O uso do termo "devem fazer" busca alinhar o comportamento à finalidade, embora possa indicar imposição, se analisado de forma isolada. Esse modo tratar os pacientes busca compreender a pessoa para além da condição de objeto de intervençâo, como também as suas especificidades, e por isso se destacam a consciência, a responsabilização e os modos como se relacionam, indicando o falar e o fazer como formas de promover mudanças comportamentais.

No contexto de atuação dos profissionais, estes relacionam a forma como o trabalho é percebido à estrutura da instituição:

o hospital tem um serviço bem estruturado que o paciente volta. [...] a informação tem sido bem dada, [...] então isso tem funcionado bem. (P1)

é bem completo seguindo os protocolos padróes mesmo. (P3) é tudo informatizado [...] então às vezes outros profissionais têm acesso. (P6)

A forma como entendem o seu trabalho e sua articulação com e na instituição contribui para a compreensão do cuidado em suas práticas, possibilitando acompanhar o antes e o depois da cirurgia:

acompanhamento mais de perto, os retornos periódicos, tudo então eu acho que isso faz com que o serviço seja melhor. (P2) Aqui eles priorizam o atendimento para a cirurgia. Então é rápido [...]. No sentido de agilização, de agilidade. (P3) 
O valor da equipe foi também destacado:

é uma equipe entrosada que segue certinho a sua rotina, trabalha em conjunto. (P2)

A gente está de mão dada [...]. Todo mundo falando a mesma lingua. (P6)

Considerar as pessoas com as quais se trabalha uma equipe, que tem entrosamento, compartilha e partilha o mesmo propósito, colabora para o cuidado:

no final você vê que eles saem satisfeitos com essa, acho que com esse sentimento de estar sendo cuidado, de estar sendo acompanhado. (P1)

A forma como os profissionais cuidam não se limita ao foco sobre a pessoa obesa, mas inclui também a relação entre os próprios profissionais e destes com a instituição, por meio de protocolos e dinâmicas de organização que se configuram como modos de trabalho alinhados ao cuidado.

\section{Considerações finais}

O estudo nos possibilitou compreender que nas práticas dos profissionais da cirurgia bariátrica se insere o cuidado, analisado em duas partes: "o valor do corpo obeso e da alimentação" e "buscando uma relação compartilhada entre profissional, usuário e instituição". No cuidado relacionam-se responsabilização e esforços profissionais diante dos aspectos sociais e culturais que os pacientes vivenciam. São reconhecidos os valores de corpo, dos hábitos e das crenças no comportamento humano, apontando para a reflexão, por parte dos profissionais, sobre o cuidado. Por isso o cuidado é complexo, uma vez que relaciona a existência das pessoas envolvidas: profissionais e usuários; implica humanidade, troca, projetos, corresponsabilidade, histórias de vida. $\mathrm{O}$ cuidado não constitui uma ação isolada, mas considera o contexto mais amplo da vida das pessoas envolvidas.

\section{Referências}

1. World Health Organization. Obesity and overweight. [Internet]. Geneva: World Health Organization; WHO; 2017 [atualizado em 2014 ago; citado em 2014 set 21]. Disponível em: https://goo.gl/E0wM1

2. Brasil. Ministério da Saúde. Portaria no 425, de 19 de março de 2013. Estabelece regulamento técnico, normas e critérios para a Assistência de Alta Complexidade ao Indivíduo com Obesidade. Diário Oficial da União. Brasília, DF; 15 abr 2013. Seção 1. p. 59-64.

3. Brasil. Aumenta número de cirurgias bariátricas realizadas pelo SUS [Internet]. Brasília, DF: Ministério da Saúde; [atualizado em 2014 jul; citado em 2014 set 21]. Disponível em: https:// goo.gl/RxT7Ho

4. Silva EG. Práticas profissionais em cirurgia para redução de peso [dissertaçáo de mestrado]. Cuiabá: Universidade Federal do Mato Grosso, 2014. 88 p.

5. Guedes CR, Nogueira MI, Camargo Junior KR. A subjetividade como anomalia: contribuições epistemológicas para a crítica do modelo biomédico. Ciênc saúde colet. 2006;11(4):1093-103.

6. Ribeiro DKMN, Maziero ECS, Silveira JTP, Betiolli SE, Mercês NNA. A identidade do cuidado de enfermagem na primeira década do século XXI. Cogitare enferm. 2013;18(3):565-72.

7. Ayres JRCM. Cuidado e reconstrução das práticas de Saúde. Interface (Botucatu). 2004;8(14):73-92.

8. Matos E, Pires DEP, Sousa GW. Relaçóes de trabalho em equipes interdisciplinares: contribuiçóes para a constituição de novas formas de organização do trabalho em saúde. Rev bras enferm. 2009;62(6):863-9.

9. Minayo MCS. O desafio do conhecimento: pesquisa qualitativa em saúde. 13a ed. São Paulo: Hucitec; 2013.

10. Brasil. Conselho Nacional de Saúde. Resolução no 466 de 12 de dezembro de 2012. Aprova as diretrizes e normas regulamentadoras de pesquisas envolvendo seres humanos. Diário Oficial da União. Brasília, DF; 13 jun 2013. Seção 1. p. 59.

11. Separavich MA, Canesqui AM. Girando a lente socioantropológica sobre o corpo: uma breve reflexão. Saúde Soc. 2010;19(2):249-59.

12. Ayres JRCM. O cuidado, os modos de ser (do) humano e as práticas de saúde. Saúde Soc. 2004;13(3):16-29.

13. Marcelino LF, Patrício ZM. A complexidade da obesidade e o processo de viver após a cirurgia bariátrica: uma questáo de saúde coletiva. Ciênc saúde coletiva. 2011;16(12):4767-76.

14. Ayres JRCM. Sujeito, intersubjetividade e práticas de saúde. Ciênc saúde coletiva. 2001;6(1):63-72.

15. Carvalho MCVS, Luz MT. Simbolismo sobre "natural" na alimentação. Ciênc saúde coletiva. 2011;16(1):147-54.

16. Vendruscolo MF, Malina A, Azevedo ACB. A concepção de obesidade e padrão corporal por mediaçóes ideológicas da mídia. Pensar prat. 2014;17(2):503-16.

17. Oliveira MAC. (Re)significando os projetos cuidativos da Enfermagem à luz das necessidades em saúde da população. Rev bras enferm. 2012;65(3):401-5.

18. Lago DBR, Maruyama SAT. Significados do cuidado no contexto da deficiência física. Cienc cuid saúde. 2014;13(2):372-80

\section{Como citar este artigo:}

Oliveira LR, Maruyama SAT, Silva EG, Costa ALRC. O cuidado nas práticas dos profissionais em cirurgia bariátrica. Rev. Aten. Saúde. 2017;15(54):83-89. 